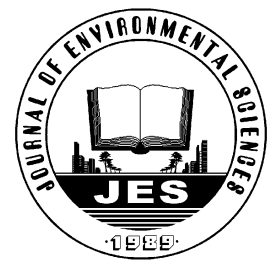

\title{
In situ DRIFTS study of hygroscopic behavior of mineral aerosol
}

\author{
Qingxin Ma, Hong He*, Yongchun Liu \\ State Key Laboratory of Environmental Chemistry and Ecotoxicology, Research Center for Eco-Environmental Sciences, \\ Chinese Academy of Sciences, Beijing 100085, China.E-mail: 5237027@rcees.ac.cn
}

Received 09 October 2009; revised 10 November 2009; accepted 19 November 2009

\begin{abstract}
In situ diffusion reflectance infrared Fourier transform spectroscopy was used to study the water adsorption on mineral oxides $\left(\mathrm{SiO}_{2}\right.$, $\alpha-\mathrm{Al}_{2} \mathrm{O}_{3}, \mathrm{MgO}, \mathrm{Fe}_{2} \mathrm{O}_{3}, \mathrm{TiO}_{2}$ ). The results showed that all the water adsorption isotherms were well fitted with the Brunauer-EmmettTeller (BET)-III type equation, with the calculated monolayers occurring at $24 \%-30 \%$ relative humidity. It showed that about $1-5$ layers of water adsorbed on oxides surfaces in ambient relative humidity (20\%-90\%). The measured deliquescence relative humidity of $\mathrm{NaCl}$ was $(74 \pm 1) \%$, which demonstrated that DRIFTS is a useful method for the study the hygroscopic behavior of mineral dust. In addition, the limits of DRIFTS were also discussed.
\end{abstract}

Key words: DRIFTS; mineral oxides; water adsorption; hygroscopicity

DOI: $10.1016 / \mathrm{S} 1001-0742(09) 60145-5$

\section{Introduction}

Mineral aerosols are produced from wind-blown soils and represent an important component of the earth's atmosphere. It is currently estimated that between 1000 and $3000 \mathrm{Tg}$ of mineral aerosols are emitted annually into the atmosphere (d'Almeida, 1987; Tegen and Fung, 1994). Mineral aerosols play an important role in the global climate change by absorbing and scattering solar radiation as well as acting as cloud condensation nucleus, which is the major uncertainty for future climate change prediction (IPCC, 2007). Modeling, field observations and laboratory study suggest that mineral aerosol could act as a reactive surface with trace atmospheric gases, thus, influencing the trace atmospheric gas budget through heterogeneous reactions (Zhang et al., 1994; Dentener et al., 1996; Usher et al., 2003), and aerosol water content has been reported to affect the uptake rate of reactive gases (Liu et al., 2009). Therefore, measurements of hygroscopic growth and associated water content are necessary to understand the radiative and chemical effects of tropospheric aerosol species.

Because it is ease for sample preparation, and it is able to analyze nontransparent materials as well as to make in situ measurement at elevated temperature, in situ diffusion reflectance infrared Fourier transform spectroscopy (DRIFTS) has been demonstrated as a useful technology for surface science and heterogeneous reactions analysis (Fuller and Griffiths, 1978; Armaroli et al., 2004; He et al., 2005). However, the utilization of in situ DRIFTS

\footnotetext{
* Corresponding author. E-mail: honghe@rcees.ac.cn
}

for the hygroscopic behavior of mineral dusts was little reported. Gustafsson et al. (2005) used the DRIFTS to study the water adsorption on calcite and Arizona test dust, and it demonstrated that DRIFTS results have a good consistency with other methods. In this study, we applied the DRIFTS to study water adsorption on mineral oxides. The influences of heterogeneous reactions with $\mathrm{NO}_{2}$ on the hygroscopic behavior change were also investigated. These results will improve our understanding of the relation between atmospheric aging processes and hygroscopicity of mineral aerosols.

\section{Experimental section}

The reaction system is depicted in Fig. 1. In situ DRIFTS spectra were recorded on a Nicolet 6700 (Thermo Nicolet Instrument Corporation, USA) FT-IR, equipped with an in situ diffuse reflection chamber and a highsensitivity mercury cadmium telluride (MCT) detector cooled by liquid $\mathrm{N}_{2}$. The sample (about $11 \mathrm{mg}$ ) for the in situ DRIFTS studies was finely ground and placed into a ceramic crucible in the in situ chamber. The total flow rate was $100 \mathrm{~mL} / \mathrm{min}$ in all flow systems, and the volume of the closed system was about $30 \mathrm{~mL}$. The samples were heated in $\mathrm{N}_{2}$ atmosphere at $100^{\circ} \mathrm{C}$ to remove surface species for $3 \mathrm{hr}$. The reference spectrum was measured after the pretreated sample was cooled to $30^{\circ} \mathrm{C}$. Nitrated oxides were in situ prepared by the reactions of the fresh sample exposed to NO $\left(200 \times 10^{-6}, \mathrm{~V} / \mathrm{V}\right)$ with stimulated air $(79 \%$ $\mathrm{N}_{2}+21 \% \mathrm{O}_{2}$ ) at $30^{\circ} \mathrm{C}$ for $2 \mathrm{hr}$ in the in situ cell. When the spectrum showed no change, the introduction of NO 


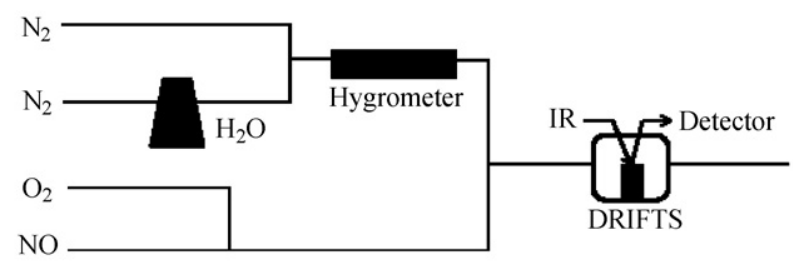

Fig. 1 Schematic of the reaction system.

and $\mathrm{O}_{2}$ were ceased and the nitrated sample was purged by $\mathrm{N}_{2}$ for $1 \mathrm{hr}$ to remove the gaseous $\mathrm{NO}$ and $\mathrm{NO}_{2}$ in the flow system. The infrared spectra were collected and analyzed using a data acquisition computer with OMNIC 6.0 software (Nicolet Corp., USA). All spectra reported here were recorded at a resolution of $4 \mathrm{~cm}^{-1}$ for 100 scans and were converted to Kubelka-Munk form directly. The low frequency cutoff below $1000 \mathrm{~cm}^{-1}$ is owing to strong lattice oxide absorptions. The relative humidity $(\mathrm{RH})$ in the reaction system, which was recorded by a moisture meter, was controlled by changing the mixture ratio of dry $\mathrm{N}_{2}$ and humid $\mathrm{N}_{2}$.

Silicon dioxide and titanium dioxide were purchased from Degussa (Germany), while $\mathrm{NaCl}, \mathrm{Fe}_{2} \mathrm{O}_{3}$, and $\mathrm{MgO}$ were purchased from Beijng Chemical Reagents Company (China). $\alpha-\mathrm{Al}_{2} \mathrm{O}_{3}$ was produced by calcinations of $\mathrm{AlOOH}$ (Shangdong Alumina, China) at $1200^{\circ} \mathrm{C}$ for $12 \mathrm{hr}$. NO (1.01\% $\mathrm{N}_{2}$, Huayuan, China) was used as received.

\section{Results and discussion}

\subsection{Adsorption of water on $\mathrm{NaCl}$}

Adsorption of water on $\mathrm{NaCl}$ was first conducted. It is a relatively simple system to study because it does not form crystalline hydrates and there is no spectral interference from the salt itself. As shown in Fig. 2a, several bands increased simultaneously with the increase of relative humidity, which are attribute to the vibration of water according to literature (Goodman et al., 2001; AlAbadleh and Grassian, 2003; Gustafsson et al., 2005). The main absorption features observed in the spectra were 3420 $\mathrm{cm}^{-1}$ with a shoulder at $3240 \mathrm{~cm}^{-1}, 2100 \mathrm{~cm}^{-1}$ and 1640 $\mathrm{cm}^{-1}$. The peak $1640 \mathrm{~cm}^{-1}$ is attributed to the bending mode of water, $\delta_{\mathrm{H}_{2} \mathrm{O}}$. For liquid water, the broad feature centered at $2100 \mathrm{~cm}^{-1}$ is assigned to an association band $\left(v_{\mathrm{a}}\right)$ which is a combination of the bending $(\delta)$, libration $\left(v_{\mathrm{L}}\right)$, and hindered translation $\left(v_{\mathrm{T}}\right)$, modes (Al-Abadleh and Grassian, 2003). The peak in the region of 2600$3800 \mathrm{~cm}^{-1}$ is a combination of $\mathrm{OH}$ vibrational modes: symmetric stretch around $3420 \mathrm{~cm}^{-1}$ and asymmetric stretch around $3240 \mathrm{~cm}^{-1}$. The absorbance of these modes is suitable to monitor water adsorption on the surfaces of the particles; therefore the integrated intensity of the $\mathrm{O}-\mathrm{H}$ stretching region provides a measure of the amount of water on the surface (Goodman et al., 2001; Gustafsson et al., 2005).

The reflected radiation in DRIFTS is dependent on many factors, including particle dimension, packing density and homogeneity, etc. (Armaroli et al., 2004). In addition,
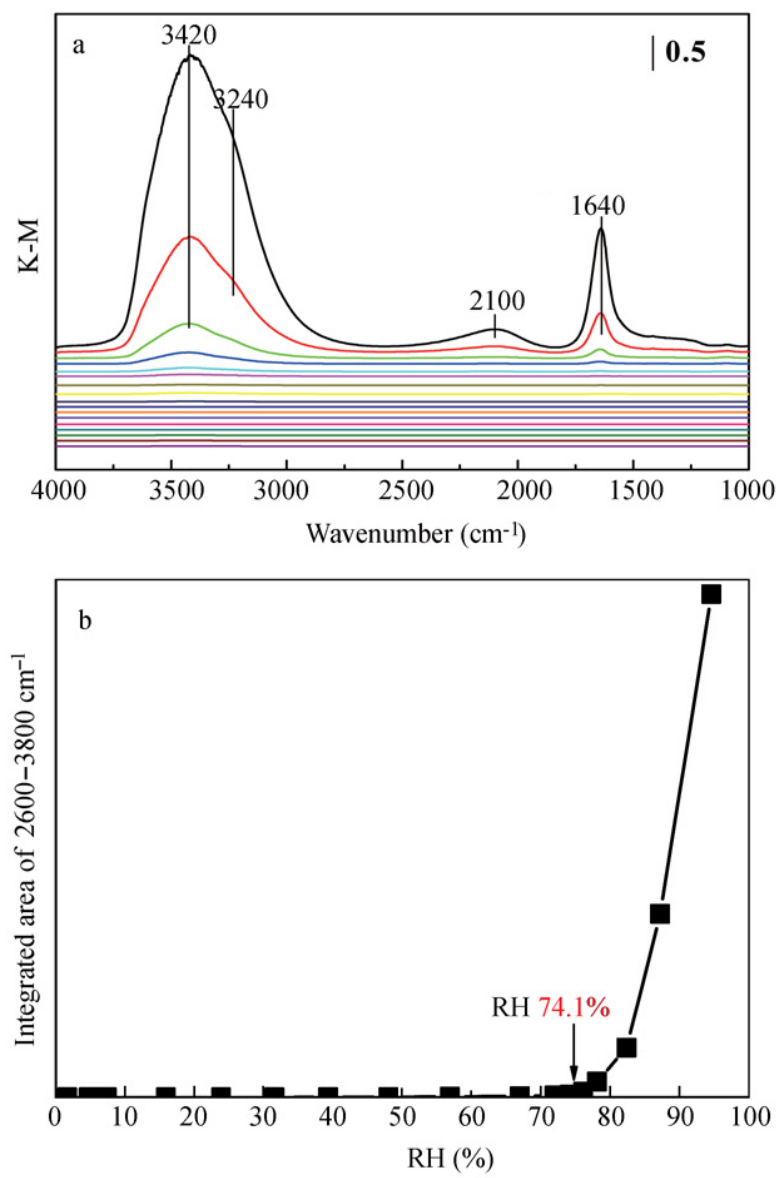

Fig. 2 DRIFTS spectra of water adsorption on $\mathrm{NaCl}$ at $30^{\circ} \mathrm{C}$ as a function of RH (\%) $(1.7,4.8,7.4,15.9,23.9,31.6,39.3,48.0,56.9,67.0,72.0$, $74.2,76.1,78.1,82.4,87.2,94.6)$ (a). Integration intensity of the bands of the region $2600-3800 \mathrm{~cm}^{-1}$ (b). RH: relative humidity.

unlike transmission FT-IR, DRIFTS shows no linear relation between band intensity and concentration. Gaining quantitative information from the spectra is non-trivial because the Beer-Lambert law used in transmittance is not applicable in this case. However, Kubelka-Munk theory can be applied to improve the linearity of the dependence of signal intensity upon concentration (Armaroli et al., 2004). The DRIFTS spectrum contains both reflection and absorption signals of incident flux on a particle. The absorption fraction is easily known from the LambertBeer law. The reflection fraction in the case of infinite thickness (2-3 mm) could be a similar expression to the absorption expression after applying the Kubelka-Munk function (Armaroli et al., 2004). Therefore, the KubelkaMunk conversion leads to a linear relationship between concentration and reflected radiation intensity for DRIFTS spectra.

There was a relatively small increase in the observed integrated absorbance of the water absorption bands under the RH value of $74.2 \%$ (Fig. 2b). When the relative humidity exceeded this value, the integrated absorbance abruptly became quite intense and continued to grow in intensity with relative humidity increasing. This sharp increase in water content of the $\mathrm{NaCl}$ particles occurred at $\mathrm{RH}$ value $(74 \pm 1) \%$. This sharp transition marked the deliquescence relative humidity (DRH) of $\mathrm{NaCl}$. This $\mathrm{DRH}$ of $\mathrm{NaCl}$ is 

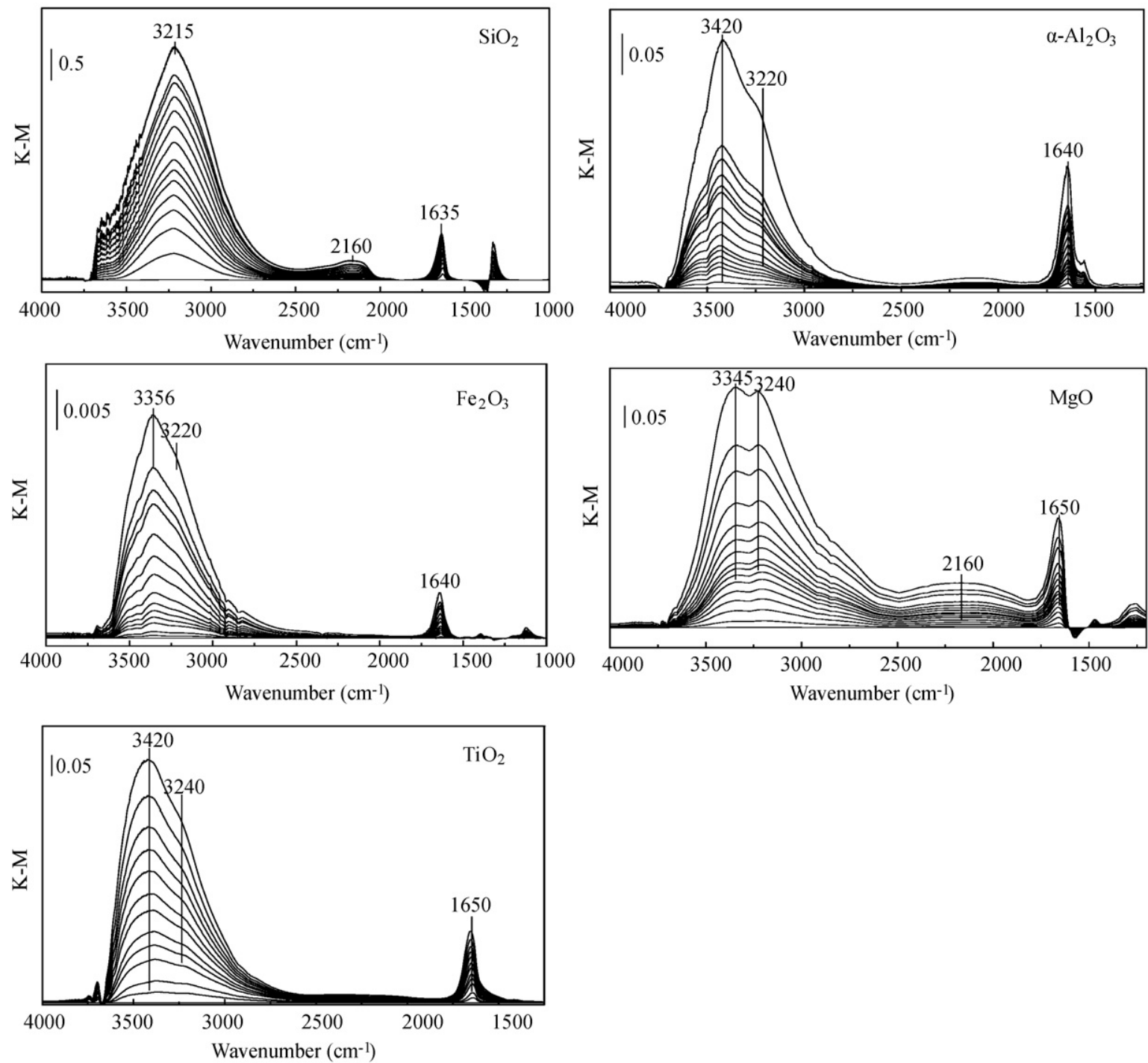

Fig. 3 DRIFTS spectra of water adsorption on $\mathrm{SiO}_{2}, \alpha-\mathrm{Al}_{2} \mathrm{O}_{3}, \mathrm{MgO}, \mathrm{Fe}_{2} \mathrm{O}_{3}, \mathrm{TiO}_{2}$ as a function of relative humidities $(2 \%-96 \% \mathrm{RH})$ at $30^{\circ} \mathrm{C}$.

in good agreement with other studies (Cziczo and Abbatt, 2000; Krueger et al., 2003).

\subsection{Water adsorption on oxides}

The DRIFTS spectra of water adsorption on $\mathrm{SiO}_{2}$, $\alpha-\mathrm{Al}_{2} \mathrm{O}_{3}, \mathrm{MgO}, \mathrm{Fe}_{2} \mathrm{O}_{3}, \mathrm{TiO}_{2}$ as a function of relative humidities are shown in Fig. 3. For all these oxides, several peaks were observed at $2600-3800 \mathrm{~cm}^{-1}, 2100$ $2200 \mathrm{~cm}^{-1}$, and $1630-1650 \mathrm{~cm}^{-1}$, which are similarly attributed to stretch mode, association mode and bending mode as mentioned above for water absorption on $\mathrm{NaCl}$. Since the IR absorption of gas-phase water was also contributed to the region of $2600-3800 \mathrm{~cm}^{-1}$ and it can not be removed by reference subtraction in different $\mathrm{RH}$, the absorption of gas-phase water was measured with a hydrophobic gold mirror as sample. The comparison of the integrated intensity of water adsorption in 2600-3800 $\mathrm{cm}^{-1}$ on $\mathrm{SiO}_{2}$ and gold mirror are shown in Fig. 4. It suggests that contribution of gas-phase water IR absorption to the surface adsorbed absorption could be neglected.

Figure 5 shows the water adsorption isotherms obtained after applying the Kubelka-Munk function to the DRIFTS

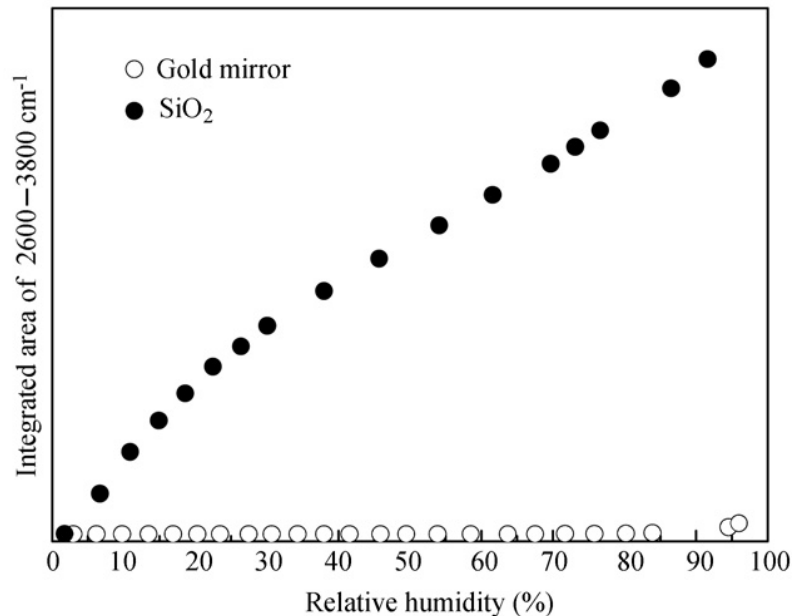

Fig. 4 Comparison of water adsorption isotherms on $\mathrm{SiO}_{2}$ and gold mirror.

data. The isotherms exhibit a type III adsorption isotherm characteristic which indicates a low adsorption enthalpy in the contact layer. It could be fitted with three-parameters Brunauer-Emmett-Teller (BET) equation with the assump- 

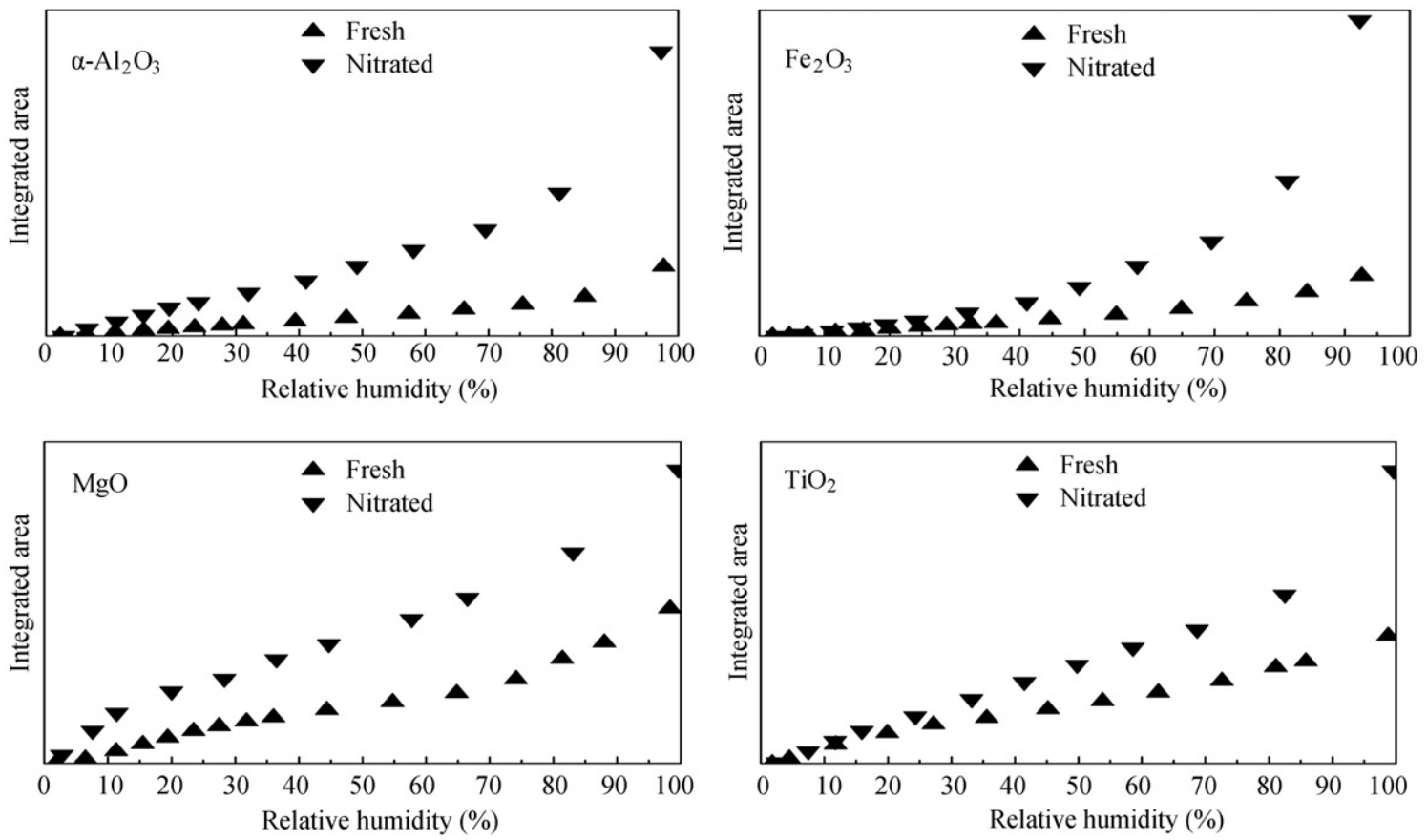

Fig. 5 Water adsorption isotherms of oxides and nitrated oxides at $30^{\circ} \mathrm{C}$. The integrated region of $\mathrm{OH}$ was in the range of $2600-3800 \mathrm{~cm}^{-1}$.

tion of limited adsorbed water layers $(n \neq \infty)$ as following Eq. (1) (Brunauer et al., 1938, 1940):

$V=\frac{V_{\mathrm{m}} c \frac{P}{P_{0}}}{1-\frac{P}{P_{0}}} \times \frac{1-(n+1)\left(\frac{P}{P_{0}}\right)^{n}+n\left(\frac{P}{P_{0}}\right)^{n+1}}{1+(c-1)\left(\frac{P}{P_{0}}\right)-c\left(\frac{P}{P_{0}}\right)^{n+1}}$

where, $V$ is the volume of gas adsorbed at equilibrium pressure $P, V_{\mathrm{m}}$ is the volume of gas necessary to cover the surface of the adsorbent with a complete monolayer, $P$ is the equilibrium pressure of the adsorbing gas, and $P_{0}$ is the saturation vapor pressure of the adsorbing gas at that temperature. $n$ is an adjustable parameter given as the maximum number of layers of the adsorbing gas and is related to the pore size and properties of adsorbent. As a result, multilayer formation of adsorbing gas is limited to $n$ layers at large values of $P / P_{0}$. The parameter $c$ is the temperature-dependent constant related to the enthalpies of adsorption of the first and higher layers through Eq. (2):

$c=\exp \left(\frac{\Delta H_{2}^{0}-\Delta H_{1}^{0}}{R T}\right)$

where, $\Delta H_{1}^{0}$ is the standard enthalpy of adsorption of the first layer, $\Delta H_{2}^{0}$ is the standard enthalpy of adsorption on subsequent layers and is taken as the standard enthalpy of condensation, $R$ is the gas constant, and $T$ is the temperature in Kelvin.
A curve-fit software (CurveExpert 1.3) was used to fit the 3 parameter BET equation for the isotherms of oxides, and the parameters calculated are shown in Table 1. The fitting curves are shown in Fig. 6. The results show that the water monolayer adsorption on oxides occurred at $24 \%-$ $30 \% \mathrm{RH}$. With the fitted value of integration intensity of monolayer, we can convert the adsorption integration

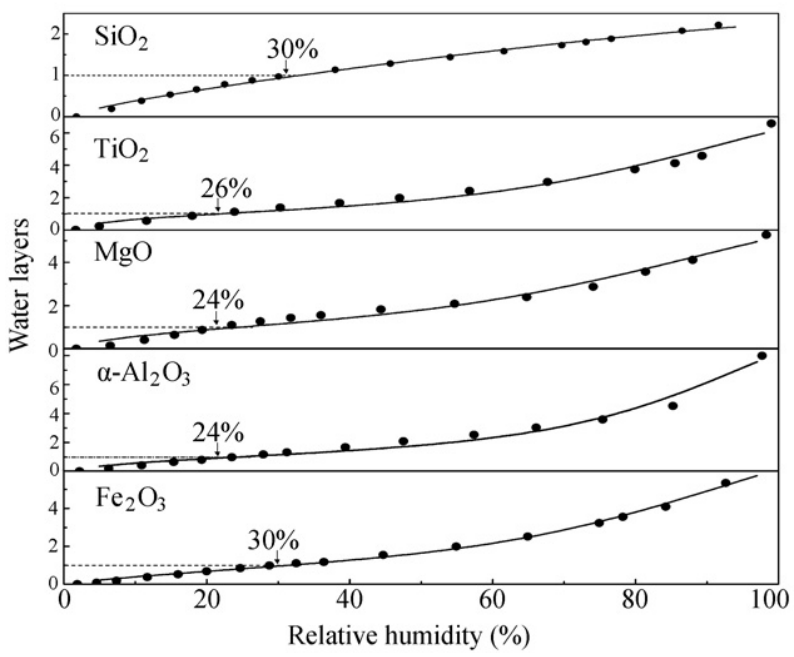

Fig. 6 Water adsorption isotherms of oxides (points) and fitting curves (lines) with III-parameters BET equation.

Table 1 Adsorption parameters for water uptake on oxide particles

\begin{tabular}{lllllll}
\hline Oxides & BET area $\left(\mathrm{m}^{2} / \mathrm{g}\right)$ & $\mathrm{M}-\mathrm{RH}(\%)$ & $n$ & $c$ & $E_{\text {ad }}$ & $P / P_{0}$ \\
\hline $\mathrm{SiO}_{2}$ & 420 & 29 & 3.8 & 4.8 & -47.95 & $1.8-92.6(0.997)^{*}$ \\
$\mathrm{MgO}$ & 14.5 & 24 & 9.5 & 9.5 & -49.67 & $1.8-98.3(0.991)$ \\
$\mathrm{TiO}_{2}$ & 12.7 & 26 & 6.2 & 5.5 & -48.29 & $1.8-95.8(0.997)$ \\
$\mathrm{Fe}_{2} \mathrm{O}_{3}$ & 2.7 & 30 & 11.3 & 4.68 & -47.88 & $1.9-92.6(0.998)$ \\
$\alpha-\mathrm{Al}_{2} \mathrm{O}_{3}$ & 12 & 24 & 15.4 & 9.66 & -49.71 & $2.2-97.7(0.990)$ \\
\hline
\end{tabular}

* Data shown in parenthesis are correlation coefficient.

$n$ : adjustable parameter; $c$ : the temperature-dependent constant; M-RH: the relative humidity where monolayer adsorbed water is formed; $E_{\text {ad }}=\Delta H_{1}^{0}$. 

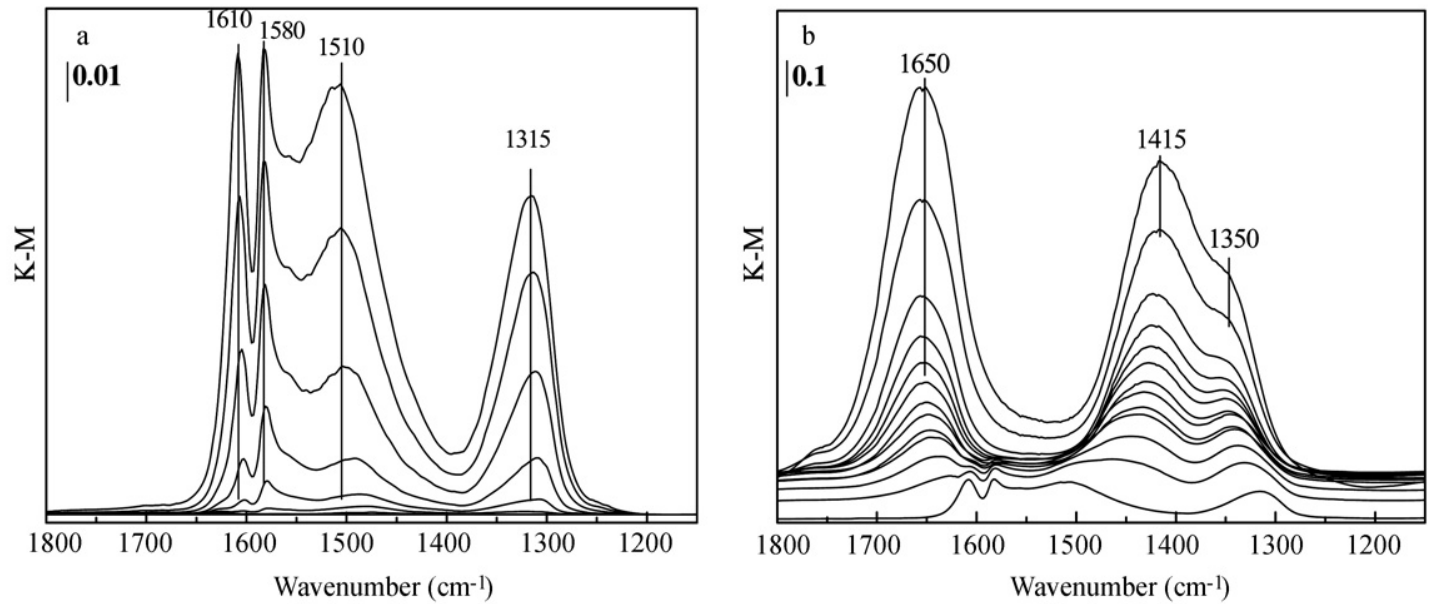

Fig. 7 DRIFTS spectra of $\mathrm{TiO}_{2}$. (a) exposure of $\mathrm{NO}\left(200 \times 10^{-6}, \mathrm{~V} / \mathrm{V}\right)$ in simulated air (total flow: $\left.100 \mathrm{~mL} / \mathrm{min}, \mathrm{O}_{2}: 21 \%\right)$ as a function of time; (b) exposed to water as a function of RH $(\%)(2.8,6.5,11.2,15.4,19.5,24.1,32.0,41.1,49.2,58.1,69.3,81.2,92.3)$ after nitrated at $30^{\circ} \mathrm{C}$.

intensity to water adsorption layers. Figure 6 shows that about 1-5 layers of adsorbed water was present in the $\mathrm{RH}$ region $20 \%-90 \%$. It was suggested that in ambient atmosphere, these mineral oxides always covered with several layers adsorbed water.

\subsection{Water adsorption on nitrated oxides}

The oxides were exposed to NO $\left(200 \times 10^{-6}, V / V\right)$ in the total flow $100 \mathrm{~mL} / \mathrm{min}$ simulated air $\left(79 \% \mathrm{~N}_{2}+21 \%\right.$ $\mathrm{O}_{2}$ ), and then the nitrated oxides were exposed to water after the introduction of $\mathrm{NO}$ and $\mathrm{O}_{2}$ ceased. The DRIFTS spectra for $\mathrm{TiO}_{2}$ are shown in Fig. 7, and several peaks at $1610,1580,1510$ and $1315 \mathrm{~cm}^{-1}$ were observed as the exposure time increased (Fig. 7a). These peaks are assigned to bridging, monodentate, bidentate, and isolated nitrate (Underwood et al., 1999; Zhang et al., 2008). The mechanism of nitrate species formation on mineral oxides surfaces were studied thoroughly (Miller and Grassian, 1998; Underwood et al., 1999). Nitrite was observed as the intermediate which was then to form nitrate species by the reactions with gas-phase $\mathrm{NO}_{2}$ in an Eley-Rideal type mechanism or with another surface nitrite in a LangmuirHinshelwood type mechanism (Underwood et al., 1999). $\mathrm{NO}$, as a gas phase product of the transformation reaction, could be oxidized to $\mathrm{NO}_{2}$ in the presence of excess $\mathrm{O}_{2}$. After this process, the oxides surfaces were covered with nitrate species. When the RH increased from $2 \%$ to $95 \%$, these peaks disappeared while the peak at 1650 $\mathrm{cm}^{-1}$ due to the bending mode of water as well as two peaks at 1415 and $1350 \mathrm{~cm}^{-1}$ which were due to watersolvated nitrate (Miller and Grassian, 1998; Goodman et al., 2001) were observed (Fig. 7b). Other oxides (expect $\mathrm{SiO}_{2}$ ) exhibited the similar spectra (not shown here). It suggests that adsorbed water significantly affect the phase of surface nitrate species. On the other hand, the influences of the reaction with $\mathrm{NO}+\mathrm{O}_{2}$ on the hygroscopic behavior of oxides are also considered. The integration intensities of water absorption for nitrated oxides are also shown in Fig. 5. It shows clearly that the amounts of water adsorption were enhanced on the nitrated oxides compared to the fresh oxides. No deliquescence process for nitrate salts was observed. The reason may be that reaction of $\mathrm{NO}+\mathrm{O}_{2}$ on these oxides in a dry condition was only limited on the surface but not to the bulk of samples. However, these results of Fig. 5 indicated that atmospheric nitrated process has an important effect on the hygroscopic behavior of the mineral oxides. It is noteworthy that, because of the limited detection depth and therefore the saturation effect, infrared spectroscopy always provides qualitative and semi-quantitative information about the species analyzed. Therefore, the extent adsorbed water amount enhanced by nitrated reaction should be further measured through other methods.

\section{Conclusions}

In this study, in situ DRIFTS was used to study water adsorption on $\mathrm{NaCl}$ and mineral oxides. It demonstrates that DRIFTS is practical for studying the water adsorption on these samples. The DRH of $\mathrm{NaCl}$ measured by DRIFTS method is $74.2 \%$, which is in good agreement with the reported data. For mineral oxides, all the water adsorption isotherms exhibited BET-III curve and the monolayers were formed at $24 \%-30 \% \mathrm{RH}$. About 1-5 layers of surface water were adsorbed at ambient relative humidity $(20 \%-90 \% \mathrm{RH})$. Using this method, we found that nitrated process could enhance water adsorption amount significantly. Although in situ DRIFTS spectroscopy is an inexpensive and convenient method to study the adsorption processes on surface, the quantitative information should be further confirmed by other methods.

\section{Acknowledgments}

This work was supported by the National Natural Science Foundation of China (No. 20877084, 20937004) and the Chinese Academy of Sciences (No. KZCX2-YW-Q0203).

\section{References}

Al-Abadleh H A, Grassian V H, 2003. FT-IR study of water adsorption on aluminum oxide surfaces. Langmuir, 19(2): 
341-347.

Armaroli T, Becue T, Gautier S, 2004. Diffuse reflection infrared spectroscopy (DRIFTS): Application to the in situ analysis of catalysts. Oil E Gas Science and Technology, 59(2): 215237.

Brunauer S, Deming L, Deming W, Teller E, 1940. On a theory of the van der Waals adsorption of gases. Journal of the American Chemical Society, 62(7): 1723-1732.

Brunauer S, Emmett P, Teller E, 1938. Adsorption of gases in multimolecular layers. Journal of the American Chemical Society, 60(2): 309-319.

Cziczo D J, Abbatt J P D, 2000. Infrared observations of the response of $\mathrm{NaCl}, \mathrm{MgCl}_{2}, \mathrm{NH}_{4} \mathrm{HSO}_{4}$, and $\mathrm{NH}_{4} \mathrm{NO}_{3}$ aerosols to changes in relative humidity from 298 to 238 K. Journal of Physical Chemistry A, 104: 2038-2047.

d'Almeida G, 1987. On the variability of desert aerosol radiative characteristics. Journal of Geophysical ResearchAtmospheres, 92(3): 3017-3026.

Dentener F, Carmichael G, Zhang Y, Lelieveld J, Crutzen P, 1996. Role of mineral aerosol as a reactive surface in the global troposphere. Journal of Geophysical ResearchAtmospheres, 101(D17): 22869-22889.

Fuller M, Griffiths P, 1978. Diffuse reflectance measurements by infrared Fourier transform spectrometry. Analytical Chemistry, 50(13): 1906-1910.

Goodman A L, Bernard E T, Grassian V H, 2001. Spectroscopic study of nitric acid and water adsorption on oxide particles: Enhanced nitric acid uptake kinetics in the presence of adsorbed water. Journal of Physical Chemistry A, 105(26): 6443-6457.

Gustafsson R J, Orlov A, Badger C L, Griffiths P T, Cox R A, Lambert R M, 2005. A comprehensive evaluation of water uptake on atmospherically relevant mineral surfaces: DRIFT spectroscopy, thermogravimetric analysis and aerosol growth measurements. Atmospheric Chemistry and Physics, 5(12): 3415-3421.

He H, Liu J F, Mu Y J, Yu Y B, Chen M X, 2005. Heterogeneous oxidation of carbonyl sulfide on atmospheric particles and alumina. Environmental Science and Technology, 39(24):
9637-9642.

IPCC (Intergovernmental Panel on Climate Change), 2007. Climate Change 2007: The Physical Science Basis. Contribution of Working Group I to the Fourth Assessment Report of the Intergovernmental Panel on Climate Change.

Krueger B J, Grassian V H, Iedema M J, Cowin J P, Laskin A, 2003. Probing heterogeneous chemistry of individual atmospheric particles using scanning electron microscopy and energy-dispersive X-ray analysis. Analytic Chemistry, 75(19): 5170-5179.

Liu Y C, Ma Q X, He H, 2009. Comparative study of the effect of water on the heterogeneous reactions of carbonyl sulfide on the surface of $\alpha-\mathrm{Al}_{2} \mathrm{O}_{3}$ and $\mathrm{MgO}$. Atmospheric Chemistry and Physics, 9: 6273-6286.

Miller T M, Grassian V H, 1998. Heterogeneous chemistry of $\mathrm{NO}_{2}$ on mineral oxide particles: Spectroscopic evidence for oxide-coordinated and water-solvated surface nitrate. Geophysical Research Letters, 25(20): 3835-3838.

Tegen I, Fung I, 1994. Modeling of mineral dust in the atmosphere: Sources, transport, and optical thickness. Journal of Geophysical Research-Atmospheres, 99(D11): 2289722914.

Underwood G M, Miller T M, Grassian V H, 1999. Transmission FT-IR and Knudsen cell study of the heterogeneous reactivity of gaseous nitrogen dioxide on mineral oxide particles. Journal of Physical Chemistry A, 103(31): 6184-6190.

Usher C R, Michel A E, Grassian V H, 2003. Reactions on mineral dust. Chemical Review, 103(12): 4883-4940.

Zhang X L, He H, Gao H W, Yu Y B, 2008. Experimental and theoretical studies of surface nitrate species on $\mathrm{Ag} / \mathrm{Al}_{2} \mathrm{O}_{3}$ using DRIFTS and DFT. Spectrochimica Acta Part A: Molecular and Biomolecular Spectroscopy, 71(4): 14461451.

Zhang Y, Sunwoo Y, Kotamarthi V, Carmichael G, 1994. Photochemical oxidant processes in the presence of dust: An evaluation of the impact of dust on particulate nitrate and ozone formation. Journal of Applied Meteorology, 33(7): 813-824. 